\title{
Conventions and Abbreviations
}

\section{CONVENTIONS}

All the dates in the book, unless otherwise indicated, are в.C.

Where taboos on the use of particular characters are observed in the book, we have systematically employed the original reading, for example, "Chu" for the name of the state and not "Jing."

There are numerous passages in The Annals of $L \ddot{u} B u w e i$ that correspond to passages in such texts as the Liji which, in their present form, are compilations that post-date the Annals. The source of Annals quotation is unknown, but presumably would be readily recognized by its audience. We have generally indented such passages to call attention to the fact that they are known to be quotations, in part because they occur in other texts.

For the Chinese text, we have generally followed the punctuation and text of Chen Qiyou, but have made a few changes where this improves understanding. Our chief concern has been the readability of the Chinese text in electronic form. We have tried to employ wherever appropriate the Big-5 forms of characters. Where there are variant forms generally recognized as the same word (e.g., in Matthews, Chinese-English Dictionary), we have adopted the form found in the Big- 5 character font. This practice contributes to the general readability of the text in electronic form. Characters that have no Big- 5 font variant have been created.

Because the translation provides a complete Chinese text of the work with full emendations, it generally does not indicate such emendations in the English text. 


\section{ABBREVIATIONS}

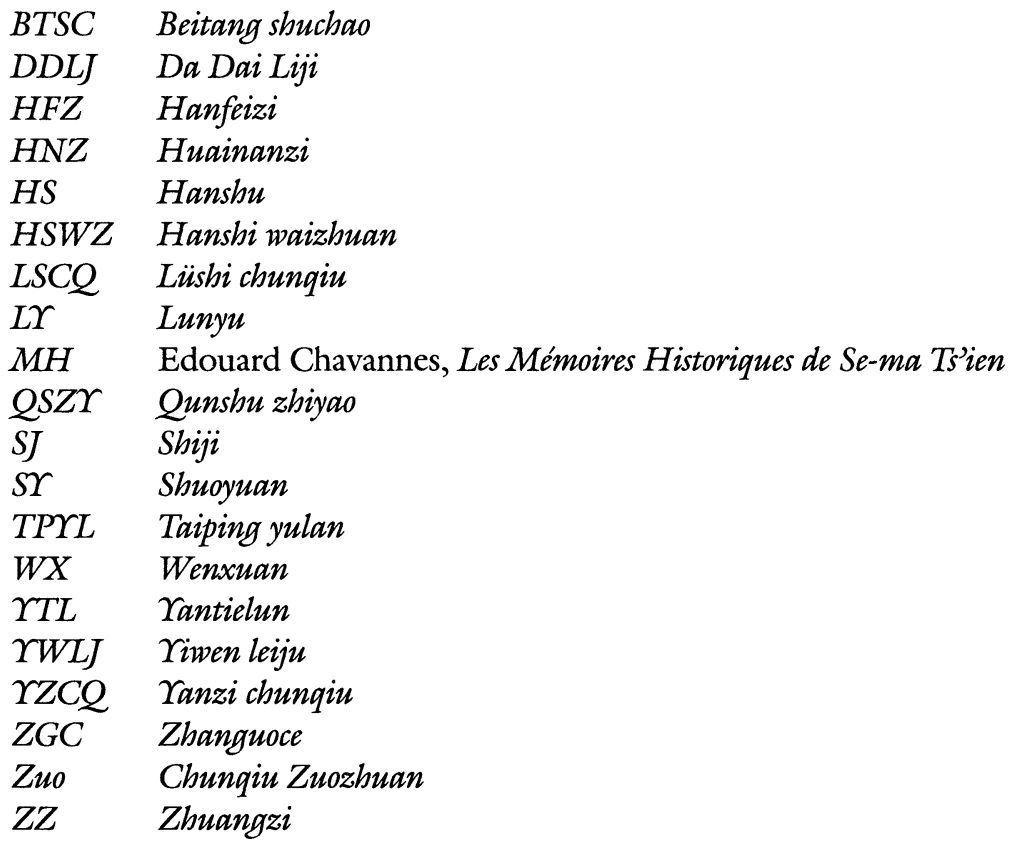

In addition, the following editorial conventions are observed in the notes to the Lüshi chunqiu:

(X) Enclosed graph (usually excrescent) should be deleted from the text.

$<\mathrm{X}>\quad$ Enclosed graph should be inserted into the text, usually from a different place in the text.

$\{\mathrm{X}\} \quad$ Enclosed graph should be inserted into the text on the basis of the reading of a parallel text.

[X] Enclosed graph should be inserted into the text on the basis of sense of text or parallelism. No corroborative evidence is available for emendation.

(X $>\quad$ Enclosed graph should be understood as the graph that follows. In these instances, $\mathrm{GE}=$ graphic error, $\mathrm{GV}=$ graphic variant, $\mathrm{LC}=$ loan character, $\mathrm{SF}=$ short form, $\mathrm{TV}=$ text variant, and $\mathrm{TA}=$ taboo avoidance.

This symbol indicates a lacuna of one character in the text. 